\title{
Concept for Floating and Submersible Wireless Sensor Network for Water Basin Monitoring
}

\author{
Marco Allegretti \\ Dipartimento di Elettronica e Telecomunicazioni, Politecnico di Torino, Torino, Italy \\ Email: marco.allegretti@polito.it
}

Received 18 April 2014; revised 13 May 2014; accepted 13 June 2014

Copyright @ 2014 by author and Scientific Research Publishing Inc.

This work is licensed under the Creative Commons Attribution International License (CC BY).

http://creativecommons.org/licenses/by/4.0/

c) (i) Open Access

\begin{abstract}
It will show the feasibility of a Wireless Sensor Network (WSN) devoted to monitoring water basin, river, lake, and sea both on the surface and in depth. The swarm of floating probes can be programmed to periodically sink some tens of meters below the surface, collecting data, characterizing water properties and then coming to the surface again. The life span of the probes may be assured by an on-board power supply or through batteries recharged by solar cells. The basic idea of the WSN is reported together with a detailed analysis of the operational constraints, the energy requirements, and the electronic and mechanical discussion.
\end{abstract}

\section{Keywords}

Wireless Sensor Network, WSN, Water Basin Monitoring, Sinkable Probes, UAV Probes, Disposable WSN

\section{Introduction}

Wireless Sensor Networks (WSNs) have attracted an increasing attention in recent years because of the large number of potential applications. They are used for collecting, storing and sharing data, for environmental monitoring application [1] [2], surveillance purposes [3], sport performance evaluation [4], agriculture [5], home automation applications and a lot of other different purposes [6].

The aim of the present paper is to show the feasibility of a Wireless Sensor Network devoted to monitoring water bodies, both on the surface and in depth.

The probes should be able to perform different tasks for various monitoring purposes. Just to give some example they could collect data on the mixing of salt and fresh water at a river estuary (Figure 1), to monitor the 


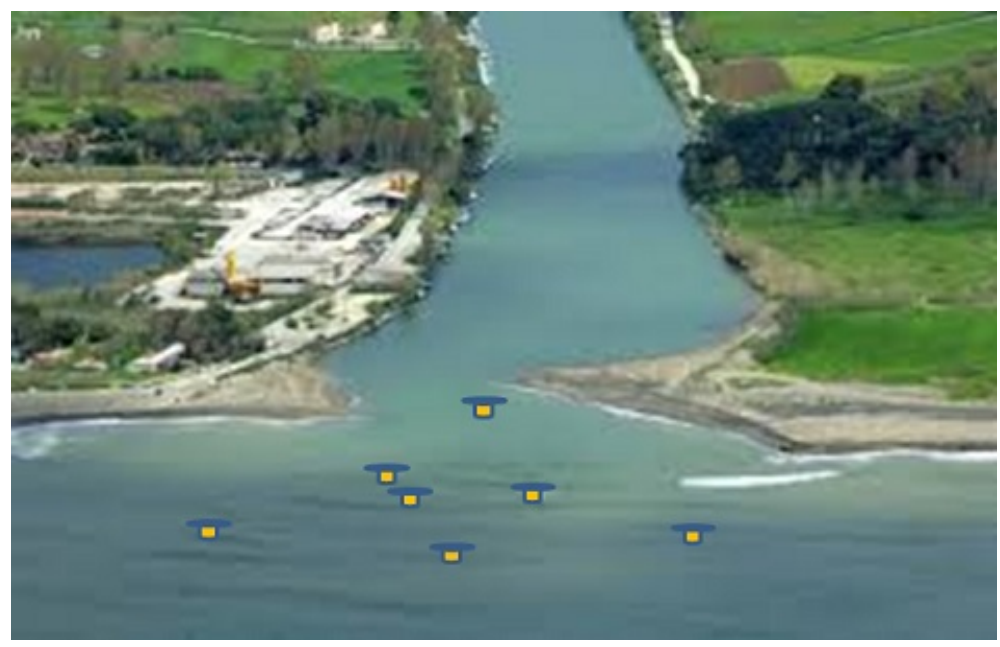

Figure 1. Example of application of the described WSNs of probes. It can be used to monitor the water at the mouth of a river.

behavior of marine currents and to collect data on lakes and water basins like temperature, salinity, pollution and so on. The monitoring operation can be done both at surface level and below the surface. The surface sea wave statistics may be collected too, just by putting a triaxial accelerometer as an additional sensor in the probe.

In addition, such probes are capable of sinking and coming back to the surface in order to collect data (in particular temperature) at various depths.

In the following, we will consider the possibility of reaching a depth even as deep as $100 \mathrm{~m}$ (obviously, when required, the depth should be programmed in function of the scientific needs), although, in most situations, depths of 10 - $20 \mathrm{~m}$ are satisfactory. Just think, for example, the need to monitor the environmental changes in the mixing of fresh water and sea water. For such application, the probes should be able to change their volume in order to change their specific weight, so being able to sink and come back to the surface. A pressure sensor can control the reached depth, triggering the operations to invert the motion by increasing the volume (and consequently decreasing the specific weight).

The shape changing requires energy which should be stored on board on each probe: it will be shown that a relatively small power supply can assure more than 100 sink and float cycles. Alternatively, energy can be collected by small solar cells.

The floating probes are disposable and can be dispersed by currents on the water surface. The collected data may be interchanged among the probes forming a Wireless Sensor Network (WSN) and finally transmitted to a GPRS system or to any other locally available data wireless network. Alternatively, the WSN may be periodically visited by an Unmanned Aircraft Vehicle (UAV): It is to be noted that the probes will move around on the surface of the water body but their spatial dispersion will be relatively limited even for time spans of a few days.

\section{Shape of the Probe and Sink/Float System}

The probes, having to float at the water surface, do not have strict requirements for what concerns weight. A single probe with a $1 \mathrm{dm}^{3}$ volume may weight just somewhat less than $1 \mathrm{Kg}$ in order to float, and therefore it can easily contain many sensors and the needed electronic. Its shape and weight do not depend strictly on the sensors and electronic inside, but mainly on the structures needed to realize the planned sink and float cycles. Therefore let us address ourselves to such a specific problem.

\subsection{Motion of the Wall}

Probably, the final shape of the probes will be some sort of a cylinder with a weight distribution such as to have the center of gravity in its lower part. However, for the sake of discussion, let us assume to have a cubic probe, just floating, having a $1 \mathrm{dm}^{3}$ volume. In order to allow it to sink, we may increase $10 \%$ its specific weight by moving one of its surfaces by $1 \mathrm{~cm}$. Of course, there is no problem with this operation when the probe is floating 
at the surface. However, at $100 \mathrm{~m}$ depth with an extra pressure of $10 \mathrm{~kg}$ per $\mathrm{cm}^{2}$, we need to apply a force to invert the motion of the surface (Figure 2).

Various techniques can be thought to implement the motion of the wall, but in order to do some order of magnitude evaluations; it is possible to assume that an endless screw is put in motion by a common stepper motor.

\subsection{Energy Requirements for the System}

The force acting on the surface is of the order of $10^{3} \mathrm{Kg}$ at $100 \mathrm{~m}$ depth, and the surface has to be moved $1 \mathrm{~cm}$ with an approximately $100 \mathrm{~J}$ work. That is not a huge amount of work, and it can be obtained by a power source delivering $1 \mathrm{~W}$ for $100 \mathrm{~s}$.

Furthermore, let us make the conservative hypothesis that the double of such energy is required, so in a practical application about $2 \mathrm{~W}$ for $100 \mathrm{~s}$ are needed (for a better and safer use of the batteries, it is better to supply something like $10 \mathrm{~W}$ for $20 \mathrm{~s}$ ); the total energy needed is approximately $0.05 \mathrm{Wh}$.

A common rechargeable battery (e.g., Energizer Rechargeable AA-2650 (HR6)) may supply 2650 mAh with $1.25 \mathrm{~V}$, consequently its full capacity is evaluated as (1):

$$
2.65 \mathrm{Ah} \times 1.25 \mathrm{~V}=3.3 \mathrm{Wh}
$$

Taking into account that it is better to not extract the entire energy from the battery, preventing a possible irreversible damage, we may state that approximately 50 cycles of immersion and rising to the surface of the probes can be performed by just one battery (with 2 AA batteries it is possible to have energy for more than 100 cycles).

In addition, very small solar cells can be applied on the top surface of the probe. Aim of the solar cell is twofold: recharge the battery and act as a sensor to evaluate the solar radiation. In fact, let us assume that the solar cell of $1 \mathrm{dm}^{2}$ can approximately collect $2 \mathrm{~W}$ per $10 \mathrm{~h}$ a day. Accumulating a total of $20 \mathrm{Wh}$, a single solar cell can be able to fully recharge 6 batteries in one sunny day.

\section{Sensors on Board}

Each probe can be equipped with a standard set of specific sensors such as:

- A triaxial accelerometer.

- 2 thermometers: The first one operates at the top, at the water-air interface, and the second one is installed at the bottom of the probe).

- A pressure gauge: To evaluate the depth at which the probe is during the immersion).

- A photovoltaic system: As stated above, the photovoltaic system can be used for two purposes: to recharge the power supply system and to evaluate the solar radiation and the solar radiation attenuation while the

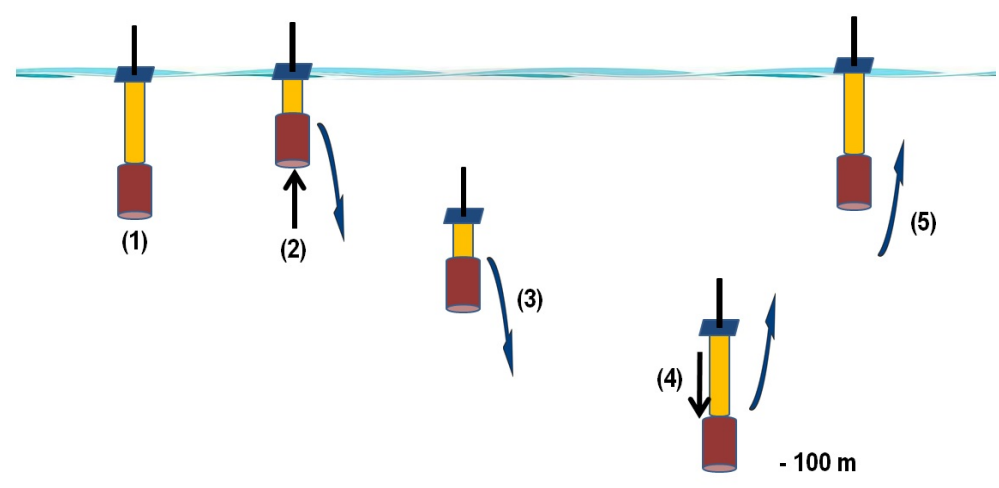

Figure 2. Operational principle of a single probe. 1) The probe is floating; 2) Thanks to the stepper motor the probe reduces its volume modifying its specific weight; 3) The probe is sinking; 4) The probe reaches the desired depth and the pressure gauge sends a signal to the stepped motor to increase the volume of the probe; 5) The probe reaches the surface. During the immersion the sensors installed on the probes measure water parameters. 
probe is sinking in the controlled way.

- A salinity sensor: It is particularly important, for example, when analyzing the mixing of fresh water and sea water)

- A GPS system: Necessary to evaluate the horizontal displacements of the probes when at the surface.

The proposed probes can also be used to monitor situations derived by accidental oil spill or by spilling of other dangerous substances; in any such situation, specific sensors can be installed on board.

\section{System Architecture}

The network of probes is intended to behave and act as a WSN.

The architecture of each node can be easily derived by tailoring the multipurpose node described for example in [7] and applying the power supply consumption techniques reported in [8]. It is to be noted that the energy consumption by the sensors is much smaller than the energy needed to move up and down the probes, taking into account that the data sampling is very low and that the sensors can be used in a low power required mode.

In [7] [9] also the architecture adopted to acquire data from the sensors (including the GPS system) is described in detail. It is useless to say that the probes can transmit data only when at the surface considering the harsh propagation conditions of the water environment.

An Access Point (AP) node, always described in detail in [7], can be used to collect data and send them to the collecting point (CP), either a fixed ground station or a UAV to be used as a bridge towards the ground station itself. The radio system may be turned on to transmit data from AP to CP in two different modes: at specific and fixed time or after a request or an inquiring coming from the CP. Depending on the specific application and area of displacement, the radio system may be simply a GPRS system or an ad hoc developed wireless data radio system. In any case, the useful range may be of many $\mathrm{km}$ assuring a good coverage of a relatively large water basin.

The AP will have a much robust power supply and it is not intended to sink; it is expected to move coherently with the swarm of the probes building the WSN, either it is a ground station or a UAV.

In addition, and for particular applications, when the swarm is not expected to have large displacements (e.g., during the monitoring operation of a closed basin or a small lake), just a single fix ground station may be needed. In such a case the node intended to be used as AP can send data directly to the ground station and the life span of the swarm is limited just by the battery life.

The proposed entire electronic system, including sensors, battery and control board, can reasonably have a total weight of $0.1 \mathrm{~kg}$, while box can have a weight of approximately $0.2 \mathrm{~kg}$. By assuming a total volume of $1 \mathrm{dm}^{3}$, and a total weight of approximately $1 \mathrm{~kg}$ and in order to be able to sink the probe by reducing the volume of $10 \%$ as described above, about $0.7 \mathrm{~kg}$ remains for the battery pack and the "mechanical" system, mainly the stepper motor.

In order to keep low the cost of each single probe, common AA batteries can be used. Each of them weighs approximately $0.03 \mathrm{~kg} .10$ batteries in each probe are weighting $0.3 \mathrm{~kg}$ leaving still $0.4 \mathrm{~kg}$ of available weight.

According to what reported in the previous paragraphs, various strategies can be adopted. As a function of the research activity to be performed, it can be chosen to use the whole amount of space for batteries without implementing any energy harvesting mechanism, or, in other situations, a systematic battery recharged procedure can be programmed.

\section{Conclusions}

The continuous monitoring of specific and detailed hydrological situations cannot be satisfactorily performed using traditional means, whether they are remotely sensing from satellites and airplanes techniques or direct measurements of the water properties with boats or ships.

Following the experience in the field of geophysical monitoring through WSNs, the approach described in this paper maybe an interesting alternative. In fact it describes the concept of disposable sounding probes that are able to collect data directly from water even at relatively significant depth (down to $100 \mathrm{~m}$ ) and operate cooperatively as a WSN.

The further steps are to build the first prototype of the system and to test it. Since the technology is fully available, no particular problem is expected in the realization of the described network of probes. 
The main technical problem is to assure the tightness of the probe when sinking till the proposed depth of 100 $\mathrm{m}$, where an extra pressure of $10 \mathrm{~atm}$ is present. It has to be note that the main critical point is the coupling of the two parts of the probe, namely the slicing part with respect to the other one. However, some tests on a cylindrical box have already been performed with positive results till a depth of $40 \mathrm{~m}$, making us to be confident to find the best solution to allow the probes to sink till the desired depth.

\section{Acknowledgments}

The present paper represents the result of a research activity promoted by the local research unit of CINFAI (Consorzio Interuniversitario Nazionale per la Fisicadelle Atmosfere e delleIdrosfere. www.cinfai.it) at DET (Department of Electronic and Telecommunications. www.det.polito.it) of Polytechnic of Turin, and developed in the framework of the Italian "Progetto Bandiera RITMARE".

\section{References}

[1] Lucianaz, C., Rorato, O., Allegretti, M., Mamino, M., Roggero, M. and Diotri, F. (2011) Low Cost DGPS Wireless Network. IEEE APS Topical Conference on Antennas and Propagation in Wireless Communications (APWC), Torino, 12-16 September 2011, 792-795. http://dx.doi.org/10.1109/APWC.2011.6046798

[2] Lucianaz, C., Diotri, F., Vagliasindi, M., Rorato, O., Mamino, M., Allegretti, M., Bergomi, N. and Roggero, M. (2011) A Low Cost Wireless GNSS Network to Trace Displacements. European Geosciences Union General Assembly 2011, Vienna, 3-8 April 2011. Poster work.

[3] Bertoldo, S., Rorato, O., Lucianaz, C. and Allegretti, M. (2012) A Wireless Sensor Network Ad-Hoc Designed as AntiTheft Alarm System for Photovoltaic Panels, Wireless Sensor Network, 4, 107-112. http://dx.doi.org/10.4236/wsn.2012.44014

[4] Le Sage, T., Bindel, A., Conway, P., Justham, L., Slawson, S. and West, A. (2011) Embedded Programming and Real-Time Signal Processing of Swimming Strokes, Sports Engineering, 14, 1-14. http://dx.doi.org/10.1007/s12283-011-0070-7

[5] Keshtgari, M. and Deljoo, A. (2012) A Wireless Sensor Network Solution for Precision Agriculture Based on Zigbee Technology, Wireless Sensor Network, 4, 25-30. http://dx.doi.org/10.4236/wsn.2012.41004

[6] Galluzzi, V. and Herman, T. (2012) Survey: Discovery in Wireless Sensor Networks. International Journal of Distributed Sensor Networks, 2012, Article ID 271860. http://dx.doi.org/10.1155/2012/271860

[7] Rorato, O., Lucianaz, C., Bertoldo, S., Allegretti, M. and Perona, G. (2012) A Multipurpose Node for Low Cost Wireless Sensor Network. IEEE APS Topical Conference on Antennas and Propagation in Wireless Communications (APWC), Cape Town, 2-7 September 2012, 247-250. http://dx.doi.org/10.1109/APWC.2012.6324911

[8] Rorato, O., Bertoldo, S., Lucianaz, C., Allegretti, M., Bertoldo, S. and Notarpietro, R. (2013) An Ad-Hoc Low Cost Wireless Sensor Network for Smart Gas Metering, Wireless Sensor Network, 5, 61-66. http://dx.doi.org/10.4236/wsn.2013.53008

[9] Rorato, O., Lucianaz, C., Vittaz, E., Bertoldo, S., Allegretti, M. and Notarpietro, R. (2012) A Wireless Sensor Network Board for Environmental Monitoring Using GNSS and Analog Triaxial Accelerometer. International Journal of Embedded Systems and Applications, 2, 35-43. http://dx.doi.org/10.5121/ijesa.2012.2403 
Scientific Research Publishing (SCIRP) is one of the largest Open Access journal publishers. It is currently publishing more than 200 open access, online, peer-reviewed journals covering a wide range of academic disciplines. SCIRP serves the worldwide academic communities and contributes to the progress and application of science with its publication.

Other selected journals from SCIRP are listed as below. Submit your manuscript to us via either submit@scirp.org or Online Submission Portal.
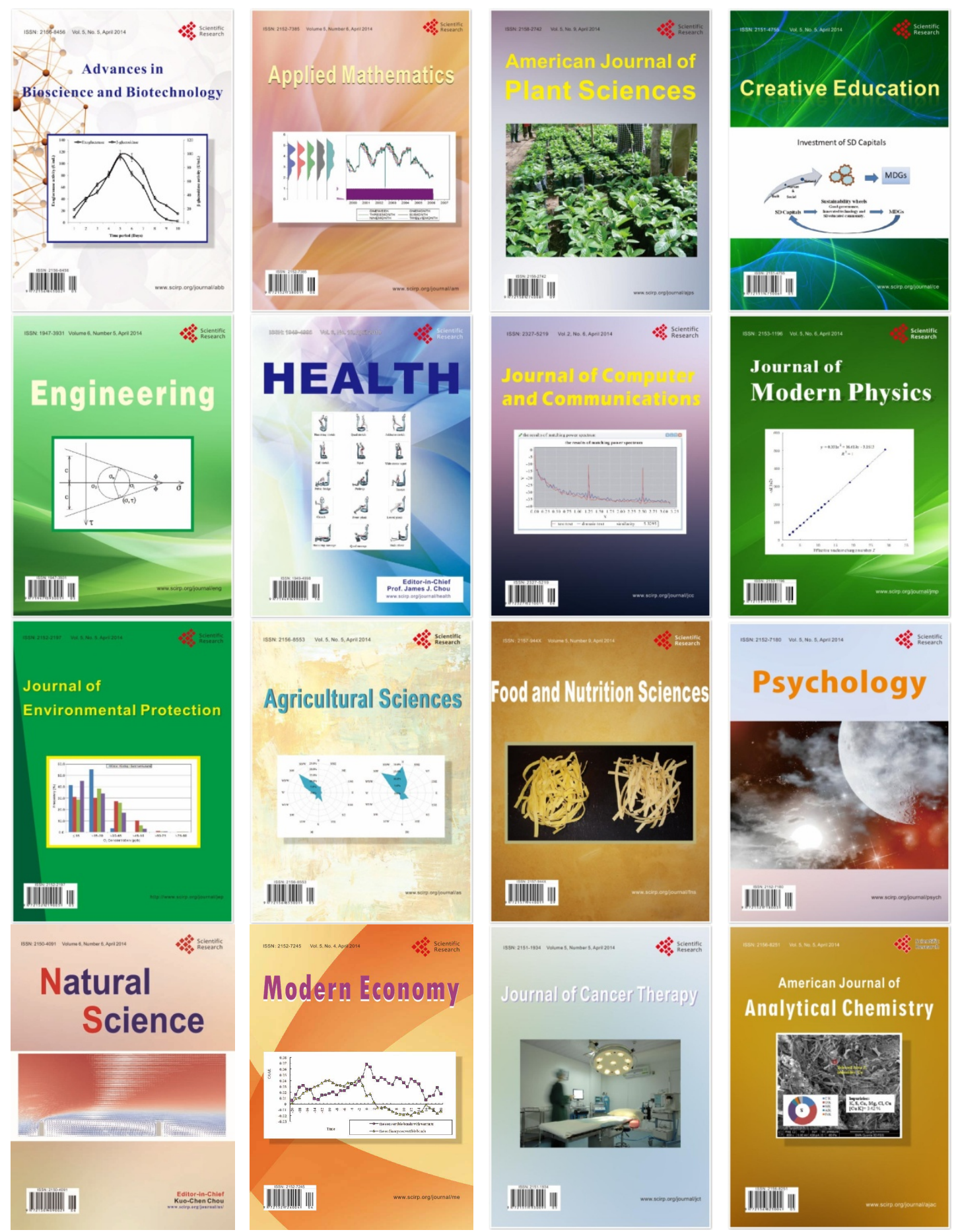